\title{
Repackaging a Mathematically Odd Bottle
}

\section{Stepan Paul creates mathematically correct sculptures to help teach complex math concepts.}

\author{
By Katherine Wright
}

C

reating art was not originally a life goal of Stepan Paul, a mathematician at North Carolina State University. Rather, he says, he stumbled into making sculptures after he got involved in a teaching project that visualizes math structures using a 3D printer. That initial foray hooked Paul, who has since hand-molded hyperbolic structures from paper and 3D-printed paraboloids from plastic. His latest piece-a "Klein bottle" that he folded from transparency film-was on display at the recent Bridges Conference, a meeting that brings together those interested in both math and art (see Physics Abounds at Conference on Math and Art).

The Klein bottle is a topological oddity, which is traditionally depicted in 3D as a "jug" whose "spout" transitions into a handle. The jug has a hole that you can pour liquid into but getting it back out is tricky (and messy). Klein bottles are like

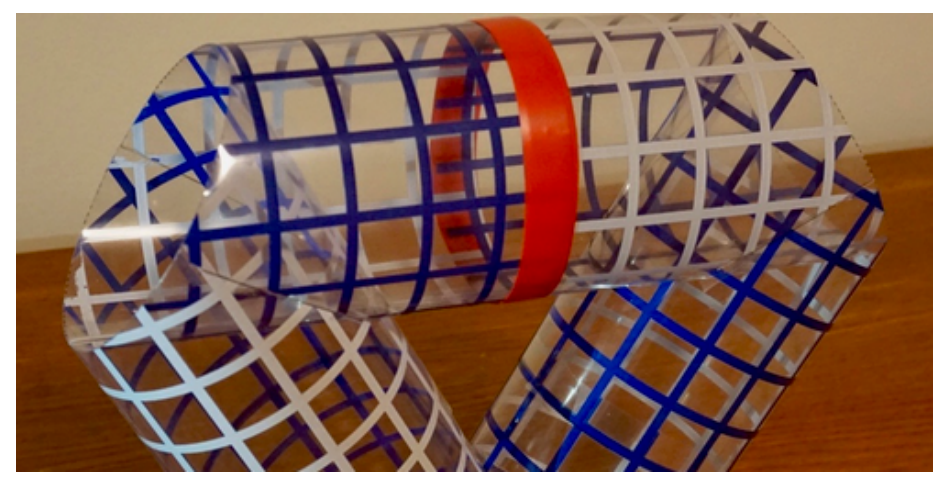

Stepan Paul hopes that his latest sculpture, which depicts a so-called Klein bottle, will help viewers visualize mathematical properties of the object that are hard to see in other renderings. Credit: S. Paul/North Carolina State University

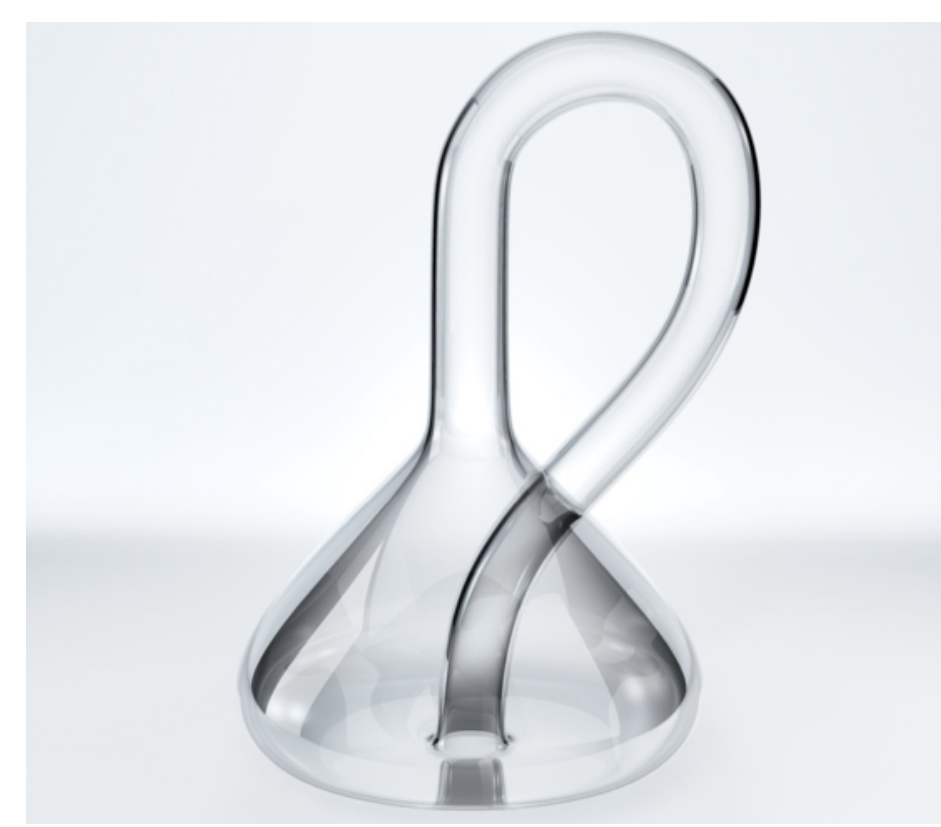

In the most common depiction of a Klein bottle, the object resembles a jug.

Credit: Yang MingQi/stock.adobe.com

Möbius strips in that they are surfaces that, if traveled upon, can take the traveler back to their point of origin while turning them upside down-leave a Klein-bottle jug's spout head up and you'll return head down. Some Klein bottles, unlike spheres or cubes, can also be flattened with no finagling: It's impossible to flatten a sphere or a cube without tearing the object or deforming its surface, while some Klein bottles can be squashed into 2D completely intact.

These weird properties can make it hard to visualize a Klein bottle. Even with a Klein-bottle jug in hand, the twists and turns 


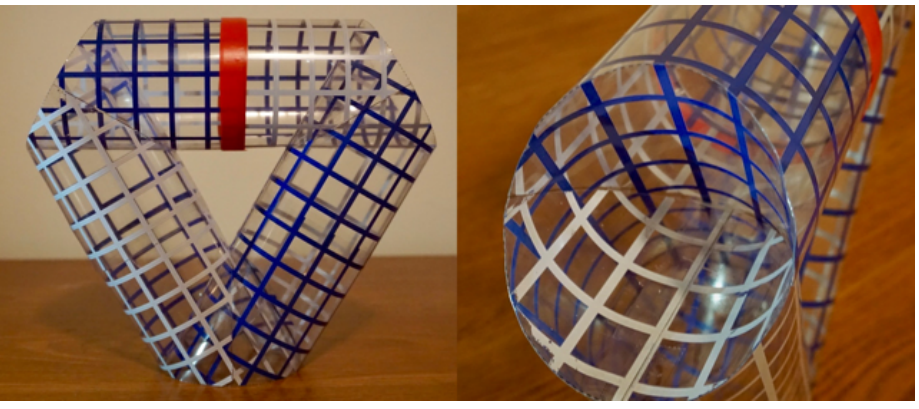

The folds of Paul's sculpture can trick the viewer into thinking that the object is flat, rather than 3D.

Credit: S. Paul/ North Carolina State University

of its surface can be hard to follow, as some of them occur inside the jug or handle. The jug also can't be flattened, Paul says, an issue he wanted to rectify.

For his Klein bottle, Paul used an origami technique known as curved crease origami, where a structure is generated from folds along curved creases, rather than straight ones. He took a transparency film, which had been printed on one side with a roughly square blue lattice and on the other with a matching white lattice. He then fashioned the plastic into a structure that resembles a triangularly folded tube whose inside and outside surfaces switch places at each vertex, as well as in the middle of one side of the structure, where the ends of the transparency are held together with red tape.

Paul says that he used the two colors to help people follow the flips of the surface. But he notes that the lattices can trick the eye a little. Viewed head on, it can be hard to believe that the creases are actually creases, he says. "You might think I cheated and taped the pieces of transparency together." But that visual impression, he says, makes it easier to imagine the object being flattened.

Paul created this Klein bottle while working from home because of the COVID-19 pandemic. As such, the sculpture has yet to be featured in one of his classes. When he does return to "in-office" work, Paul says that he plans to put the sculpture on a shelf in his office, where he hopes it will captivate passing students and spark a conversation between him and them. "I'm always interested in attracting people into math who might otherwise not have thought about studying it," he says. "Art has great outreach potential."

Katherine Wright is the Deputy Editor of Physics. 